\title{
All the Production Costs of Intensive Livestock Farming: A Graphical Representation
}

\author{
Anna Pellanda* \\ Department of Law, Retired Full Professor of Political Economy, University of Padua, Italy
}

*Corresponding Author: Anna Pellanda, Department of Law, Retired Full Professor of Political Economy, University of Padua, Italy.

Received: January 31, 2022; Published: February 05, 2022

DOI: 10.55162/MCAES.02.017

\section{Introduction}

In microeconomics, the costs of intensive livestock farming are studied in the short and long term, just like any normal production costs, and they are represented by means of an envelope curve, but this approach is unable to illustrate them all. Nowadays, we speak of the "hidden" and/or social costs as well. The former are only hidden to those who prefer not to see them, and the latter contribute to the concept of economic costs. This wider view of the problem of production costs needs to be graphically represented, so here we propose a revised version of the envelope curve that succeeds in revealing all the costs of intensive livestock farming. The outcome is an L-shaped curve instead of a U-shaped one.

Given the dimension of intensive livestock farms, we examine all the costs in terms of economies and diseconomies of scale. Taking this approach makes the incidence of the diseconomies immediately obvious, and a novel graphic representation has to adapt. Instead of merely describing the present, it should also indicate the future trend: and we discover that, in the longer term, all the production costs are so high that they become unsustainable.

\section{Economic costs and economies of scale}

The economies of scale achieved by intensive livestock farms are both pecuniary and real, and derive from the huge scale of the installations where the animals are raised, and from the technical/pharmacological measures taken to enable them to operate. The monetary economies include discounted prices on massive quantities of animal feed (not hay or grass) and on the costs of transporting large numbers of animals to slaughterhouses (with an atrocious disregard for their welfare en route). Real economies are achieved by housing the livestock in vast sheds, exploiting every inch of the available space inside and out. The animals stand shoulder to shoulder unable to move, even when a sow's piglets are born, and chickens are prevented from opening their wings. The other great source of economies of scale lies in pharmacological rather than technical advances. Given the overcrowded conditions in which they live, the animals are given antibiotics to prevent the spread of disease. The FAO has calculated that $70 \%$ of all antibiotics produced around the world are administered to livestock. They are also fed hormones in huge quantities because the animals have to become "profitable" as soon, and as often as possible. They have to be fattened and able to reproduce extremely quickly. To give an example: in the natural world, cows can live up to 20 years and produce seven calves; those farmed intensively have to produce a calf every year, and live five years at most, by which time they are exhausted, so they are slaughtered. 


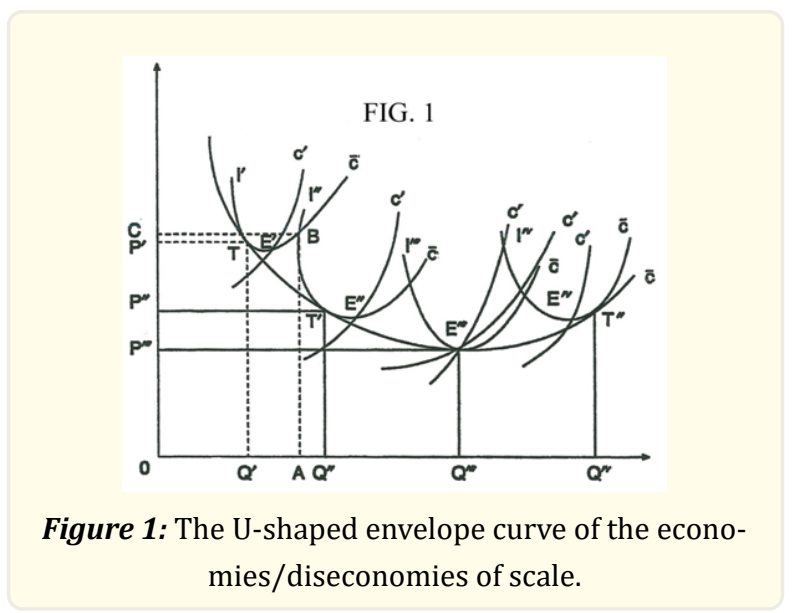

Economies of scale can be graphically represented with a U-shaped envelope curve [1], where industrial plants (I', I", I"')are shown with their marginal $\left(c^{\prime}\right)$ and mean $(c)$ costs. The first plant, $I^{\prime}$, is said to be underused because, instead of using it up to the optimal point $E^{\prime}$ (where the marginal and mean costs converge), it is used up to the point $\mathrm{T}$, where the costs are falling. It is even less worthwhile to produce at $\mathrm{B}$, where the cost $\mathrm{AB}$ would exceed Q'T. Instead, we move on to plant I", where the quantity OQ" $>0 \mathrm{O}$ is sold at the price OP", which corresponds to the cost Q' T'. But plant I" is also only used up to the point T', not to the optimal point E" (where the marginal and mean costs converge) because, here again, the costs are dropping in this phase. We can go from one plant to another in search of the best of all, which is plant I'" at the point E'”. An envelope curve touches the points E', E" and E', and we can see that production is optimal in E"', where the short-term marginal and mean costs, and the long-term mean costs (or envelope curve) and related marginal costs converge. The prices reflect the trend of the costs, so the quantity OQ' is sold at the price OP' (Q'T), the quantity Q' Q' at the price $O P{ }^{\prime \prime}\left(Q^{\prime \prime} T\right.$ '), and the quantity Q" $Q^{\prime \prime \prime}$ at the price $O P^{\prime \prime \prime}\left(Q^{\prime \prime \prime} E^{\prime \prime \prime}\right)$. In other words, when costs fall, production increases, and products are sold at lower prices, thereby achieving economies of scale. But, beyond the optimal point E'”, the short-term economies of scale (i.e. gained with the large but not enormous plants I', I", I"') come to an end, and diseconomies of scale emerge. The point E'”marks the cutoff between economies and diseconomies of scale. Insisting on producing at plant $\mathrm{I}^{\mathrm{IV}}$ in the short term means producing at rising mean and marginal costs, and is not worthwhile. But even using a huge plant cannot escape the rise in costs, as the L-shaped envelope curve demonstrates: beyond the point $E^{\prime \prime}$, the internal and external diseconomies - or, in other words, the hidden and social costs of production - inexorably make their appearance.

\section{"Hidden" costs, social costs and diseconomies of scale}

Diseconomies of scale may be internal or external. From the standpoint of economic theory, internal diseconomies are due to management problems and inefficiencies, while external diseconomies stem from a shortage of the inputs needed for production, or in other words from the fact that resources become more and more scarce as the quantities produced increase. This explanation is not enough in the case of intensive livestock farms, however, because what happens is that while the price of beef, pork, poultry, chickens, or fish remains low, the damage to the environment and to human health is very high. These are the so-called "hidden" costs, thus named because people are generally unaware of them.

Already in 2006, a report from the FAO [2] described the negative impact of certain farming methods on the environment, but the gravity of the problem has only become clear in recent years. In Italy, an investigation published on 10 March 2021 - commissioned by the LAV (an antivivisection association) and conducted by the Demetra company - focused especially on the hidden costs of meat consumption. These costs affect society as a whole, but have long been kept under wraps by meat producers, whose attention is directed towards the private profit, while the losses are "socialized" - in other words, it is the consumer (whose health suffers) and the

Citation: Anna Pellanda. "All the Production Costs of Intensive Livestock Farming: A Graphical Representation". Medicon Agriculture \& Environmental Sciences 2.3 (2022): 01-03. 
environment (through air and water pollution) that pay the price. These costs are difficult to quantify in monetary terms, however. The University of Oxford [3] attempted to do so by calculating, for instance, the costs incurred by human diseases caused by a meat-rich diet. Taking this approach, these costs could be better described as "social costs".

The first theoretical analysis on these costs was published in 1963 by K.W. Kapp [4], who considered the damage caused to human health, the destruction of the environment, and a weakening of human values (that, in the present author's opinion at least, include the deterioration in the relationship between humans and animals). Taking these issues one by one, some costs have become abundantly clear. (a) Human health suffers when people eat meat from animals raised not on hay and grass, but largely on soy and cereals, antibiotics and growth hormones. These animals also suffer from the stress of a short life in desperately inhumane conditions, and a journey from farm to slaughterhouse without rest, water or food. (b) The environment is being destroyed by deforestation of vast tracts of land, as in the Amazonian rainforest, where trees are felled to make way for soy and cereal crops. The environment is also being polluted by greenhouse gases coming from intensive livestock farms, where animal droppings and anaerobic digestion systems produce methane, nitrogen, ammonia and carbon dioxide (all causes of global heating and acid rains), while groundwater is contaminated by the effluent from the farms. (c) Human values seem to have become a mirage; the suffering inflicted on the animals is unheard of, and it has taken the courage of a few animalist associations like the CIWF and the WWF to overcome all kinds of obstacle and succeed in documenting the horror.

Unless all these costs are reduced by shutting down intensive livestock farming practices and convincing consumers to change dietary habits, their trend on the graph is bound to take on the shape of a line parallel to the Y-axes, where they are infinitely high (Fig. 2) and human destiny will reach its terminus. Then Keynes's prediction will come true: in the long run we are all dead.

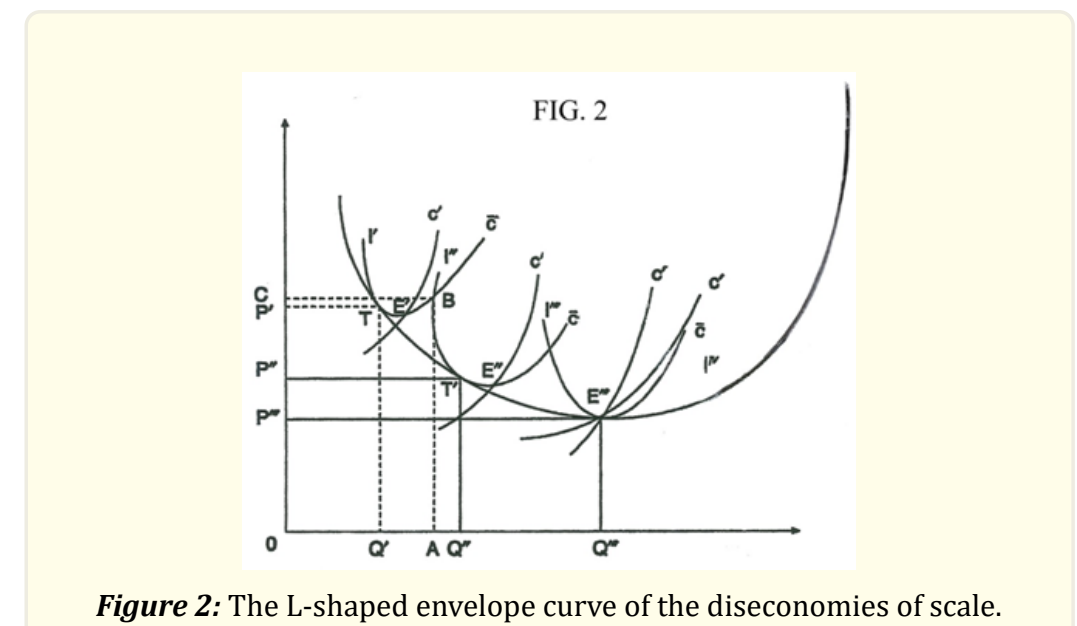

\section{References}

1. VINER J. “Cost Curves and Supply Curves”, Zeitschrift fuer Nationaloekonomie, Bd. III (1931): 23-46.

2. Livestock's Long Shadow: Environmental Issues and Options.

3. Public Library of Science ONE (2018).

4. KAPP KW. The Social Costs of the Business Enterprise (1950), London, Asia Publishing House (1963).

Volume 2 Issue 3 March 2022

(C) All rights are reserved by Anna Pellanda. 